\title{
Application of a Bayesian Network Complex System Model Examining the Importance of Customer-Industry Engagement to Peak Electricity Demand Reduction
}

\author{
Desley Vine ${ }^{1}$, Laurie Buys ${ }^{2}$, Jim Lewis ${ }^{3}$, Peter Morris ${ }^{2}$ \\ ${ }^{1}$ School of Electrical Engineering and Computer Science, Science and Engineering Faculty, Queensland \\ University of Technology, Brisbane, Australia \\ ${ }^{2}$ School of Design, Creative Industries Faculty, Queensland University of Technology, \\ Brisbane, Australia \\ ${ }^{3}$ Science and Engineering Faculty, Queensland University of Technology (QUT), \\ Brisbane, Australia \\ Email: ‘d.vine@qut.edu.au, I.buys@qut.edu.au, james.lewis@connect.qut.edu.au,pmorris.au@gmail.com
}

Received 22 March 2016; accepted 28 May 2016; published 31 May 2016

Copyright @ 2016 by authors and Scientific Research Publishing Inc.

This work is licensed under the Creative Commons Attribution International License (CC BY).

http://creativecommons.org/licenses/by/4.0/

(c) (i) Open Access

\section{Abstract}

This paper explores the importance of customer-industry engagement (CIE) to peak energy demand by means of a newly developed Bayesian Network (BN) complex systems model entitled the Residential Electricity Peak Demand Model (REPDM). The REPDM is based on a multi-disciplinary perspective designed to solve the complex problem of residential peak energy demand. The model provides a way to conceptualise and understand the factors that shift and reduce consumer demand in peak times. To gain insight into the importance of customer-industry engagement in affecting residential peak demand, this research investigates intervention impacts and major influences through testing five scenarios using different levels of customer-industry engagement activities. Scenario testing of the model outlines the dependencies between the customer-industry engagement interventions and the probabilities that are estimated to govern the dependencies that influence peak demand. The output from the model shows that there can be a strong interaction between the level of CIE activities and interventions. The influence of CIE activity can increase public and householder support for peak reduction and the model shows how the economic, technical and social interventions can achieve greater peak demand reductions when well-designed with appropriate levels of CIE activities.

*Corresponding author.

How to cite this paper: Vine, D., Buys, L., Lewis, J. and Morris, P. (2016) Application of a Bayesian Network Complex System Model Examining the Importance of Customer-Industry Engagement to Peak Electricity Demand Reduction. Open Journal of Energy Efficiency, 5, 31-47. http://dx.doi.org/10.4236/ojee.2016.52004 


\title{
Keywords
}

\author{
Peak Electricity Demand, Residential Electricity, Complex Systems Modelling, \\ Customer-Industry-Engagement
}

\section{Introduction}

Peak or maximum electricity demand is an international policy issue as governments and utilities search for ways to avoid the increased infrastructure costs of generation and network expansion required to meet spikes in demand. These spikes in electricity demand in Australia occur infrequently, for less than 40 hours per year (i.e. less than $0.5 \%$ of the year) often in response to unusually hot or cold weather [1] [2]. Reducing demand for peak electricity not only avoids expansion costs that will otherwise have to be passed onto consumers, it also avoids the risk of blackouts and helps governments with climate change targets by reducing emissions from generation fuels and encouraging low carbon communities [3] [4].

Residential consumers are an important group when considering peak energy demand management because Australian households are said to contribute around two-thirds to peak demand levels though they only account for around 25 per cent of total electricity consumption [2]. The key driver of residential peak electricity demand is consumption behaviour for lighting, cooling, heating, appliances and technology. While the key driver is consumption behaviour, the prevailing strategies employed to manage peak demand have been time-based tariffs, smart meters and direct load control of appliances. Such strategies fall within the physical, technical and economic (PTE) category based on the logic of proven and replicable science and idealised consumer behaviour [5].

\subsection{Physical Technical and Economic (PTE) Strategies}

The economic and engineering approach of the physical-technical-economic model (PTEM) of energy consumption has had significant influence in energy analysis, demand forecasting and the creation of policy [6]-[8]. Such models have a heavy reliance on technical and economic theories which assume efficiency to be driven by price and for energy consumption to be relatively homogenous. In PTEMs, changes in consumer demand and patterns of energy use are determined by changes in technologies, predominately driven by the cost of energy relative to consumer income (Lutzenhiser cited in [9]). A lot of energy policy has overstated the importance of technology and energy prices [10] and has accepted the ideal, rational individual as self-evident [11]. However, research results indicate that residential-sector consumption is characteristically unpredictable and changeable, has non-economic motives and also has significant social contexts of consumption over both the short and long term flow of energy [8] [12]. Therefore, there are factors other than the physical technical and economic which heavily influence residential energy consumption. The human dimension of energy use plays a significant role and yet has been largely overlooked in comparison to PTE models [13].

\subsection{The Importance of Consumer Behaviour and Social Factors}

Social and behavioural science research on residential energy conservation, efficiency and demand side management has reviewed individual and contextual factors of influence to energy consumption and the adoption of energy conserving practices [5] [14]-[18]. Studying and modelling human behaviour sets consumption as an individual behaviour which implies that people make completely sovereign choices, thereby discounting the effect of social expectations such as those relating to proper care of the family, definitions of comfort and healthy living and presumed social expectations of guests [19]. According to anthropologists and sociologists, energy models should consider the social context of individual actions because they believe that human behaviour is social and collective [8]. They have studied people's everyday practices (such as bathing, cleaning, cooking) and used the findings to explore how these practices affect energy use. Anthropologists and sociologists consider individual choices to be determined by technological and social systems and for any change in energy use to be the result of a wider social change.

\subsection{Attempts to Influence Individual Behaviour}

Communication has been the intervention tool employed in the majority of studies attempting to influence indi- 
vidual energy related behaviour (see reviews undertaken by [16] [17] [20]). While not all information programs are effective [21] those that use feedback and a more personalised approach have yielded the best results [16] [22] [23]. Information can be personalised or tailored on the basis of different criteria, including, current behaviour (e.g. energy saving options relevant to a particular household) and motivations (e.g. environmental, economic or community concerns) [24]. It is suggested that the most effective forms of feedback are likely to include products (e.g. in-home-displays, meters, etc.) and services (targeted and tailored recommendations, home energy assessments, data compilation, etc.) personalised and contextualised to the consumer to provide meaning and motivation [25] [26]. However, information by itself is insufficient to motivate consumers to conserve energy but has been found to work well with other instruments like, goal setting, commitment, financial incentives and engaging residents in small, actionable steps on "how to" conserve [20] [26]. Information also needs to be supplied by a trusted and credible source [27].

\subsection{Customer-Industry Engagement (CIE)}

Those tasked with communicating information regarding energy conservation and efficiency need to understand consumers' motivations to conserve energy (e.g. saving money, environmental or sustainability concerns, etc.) and to construct relevant messages to consumers [28]. How the electricity industry engages with their residential customers to affect peak energy demand has potentially important direct and indirect influence on consumer demand and therefore behaviour. For example, developing peer status and a partnership relationship between the utility and the customer can ease communication flow and establish trust thereby enabling targeted knowledge and information transfer that equips and motivates consumers to reduce their peak energy consumption [29]. Having information delivered by a trusted source is important to the success of the message being received [20] [30]. When the consumer views the information provider as a trusted professional, the interaction can lead to the opportunity of clarifying or explaining confusing topics such as the use of tariffs, bringing positive benefits to both the residential consumer and electricity industry [8] [30]. However, the treatment of customer-industry engagement with regard to energy conservation and peak electricity demand has been limited to rhetoric of deliberative engagement that does not transpire [31] or to the interaction between smart meters and the householder (for example, see [32]-[34]) even though improvements to the relationship between industry and the customer could reap significant reduction of peak energy demand.

This paper examines the contribution of residential customer-electricity industry engagement in enhancing the outcomes of physical technical and economic initiatives in reducing peak energy demand. This paper does this through scenario testing application of a newly developed complex systems Bayesian network (BN) model entitled the Residential Electricity Peak Demand Model (REPDM) (see Figure 1) to gain insight into the impact of customer-industry engagement on PTE strategies in affecting peak energy demand.

\subsection{Complex Systems-BN Model}

Supply and demand of electricity operates within a complex system that cannot be condensed to a simple justification or policy approach [6] [35]. Any attempt to alter residential electricity use needs to influence the entire socio-technical-economic system to achieve success [36]. These attempts, however, are often difficult to conceptualise and understand due to the number of interacting factors [37]. One way to conceptualise and understand the complexity of residential energy use is through a systems approach that dynamically models complex systems [38]. Such an approach improves comprehension of the complexity, the likely impact of any intervention and enables reliable predictions of changes and knock-on effects to be made [39]. A Bayesian Network (BN) is a dynamic system model that can deal with a variety of information sources and complexity of interactions [40].

BNs have been used across diverse fields including health, robotics, ecology, forensic science and defence and present an intuitive method of visualising the complex system [41]. They are particularly useful where there is a lack of accessible data as is the case with residential energy use. Like the development of most BNs, the REPDM was developed using stakeholder input. The REPDM was developed by an expert committee of academic and industry representation with mathematics, statistics, engineering and social science disciplines represented. Using integrative models developed by Van Raaij and Verhallen [42] and Keirstead [6] as a basis, the expert committee explored the distinct factors and workings of the complex system of Australian residential peak energy demand and determined the REPDM structure and parameters. The design process involved identifying 


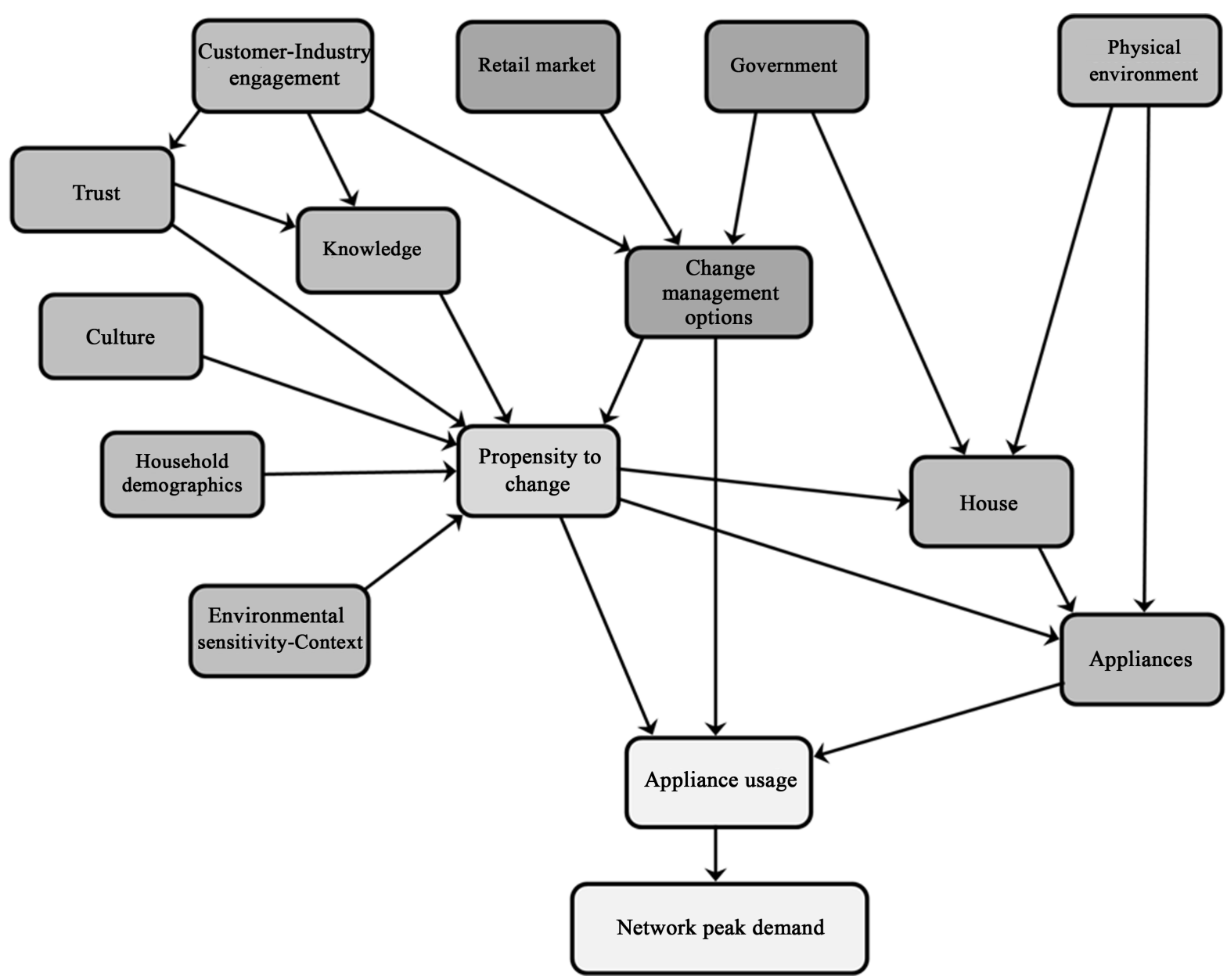

Figure 1. The residential electricity peak demand model.

the nodes and the interactions between them. As can be seen in Figure 1, the REPDM is presented in graphical form, to demonstrate the relationships within the complex system network which is residential energy use. The model integrates physical and technical aspects of influence on peak electricity demand, including appliances, housing type, location and climate conditions together with the economic and social aspects of influence on or to the household including but not limited to customer-industry engagement, culture, practice, demographics and degree of environmental concern. The expert committee also developed and populated the model's associated probability tables informed by experience as well as quantitative and qualitative data available to the energy utility and the researchers (see [43] for a description of the model building process).

\subsection{Context of Current Study}

This paper explores the importance of customer-industry engagement to peak energy demand by means of a newly developed BN model entitled the Residential Electricity Peak Demand Model (REPDM). The REPDM incorporates (or is based on) a multi-disciplinary perspective integral to solving the complex problem of residential peak energy demand. The model was developed through a complex systems theory approach as a way to conceptualise and understand the factors that shift and reduce consumer demand in peak times. The purpose of this paper is to gain insight into the importance of customer-industry engagement on PTE strategies in affecting residential peak demand. This is achieved by investigating intervention impacts and major influences through testing five scenarios using different levels of customer-industry engagement activities. Scenario testing of the model outlines the dependencies between the customer-industry engagement interventions and the probabilities that are estimated to govern the dependencies that Influence peak demand. 


\section{Methods}

This paper explores the impact of changes in the level of Customer-industry engagement on the Propensity to Change the Peak Demand for electricity by residential households. This was undertaken by using the in the systems model, the REPDM [43], which was developed as a BN to enable the reduction of peak demand under different interventions to be quantified. The REPDM BN allows for quantification of causal impacts with nodes indicating factors which influence an outcome (input nodes) or form a relationship influenced by other elements of the peak demand system [44]. The lines represent the direct dependencies between the nodes. The full REPDM combines technical, economic and behavioural systems. It can accept data in an integrated, coordinated approach and can be used for policy design with scenario testing and as a measurement tool. Its application for this paper is to scenario test customer-industry engagement to understand the impact of this often underestimated/ undervalued factor on influencing/affecting residential peak electricity demand.

\subsection{Development and Modifications in Model}

The development of the quantified systems model, as described in [44], involved integrating the elements of the model in a BN that combining technical inputs in a Microsoft Excel spreadsheet which calculated changes in peak demand under different scenarios of interventions. The model development was undertaken using group processes and expert elicitation in workshops with industry informants. A BN is a graphical approach that may be used to aid decision making by calculating the interactions between nodes of a system [40] [41]. It allows for the quantification of these interactions in complex systems with multiple interacting nodes to provide outputs that, in the case of the REPDM, allow scenarios to be investigated and options to be investigated.

The ongoing development process with the REPDM has led to iterative updating and improvement to various aspects of the model. The Conditional Probability Tables (CPTs) for some nodes were reviewed in this process and updated following further consideration of the outputs of those nodes and the underpinning social dimensions of the interactions concerned. The new CPT values (Appendix 1) were used to model the impact of the Change Management options.

\subsection{Change Management Options Modeled}

Many options are available for energy suppliers and governments to assist the process of reducing network peak demand. A selection of the range of these options was modeled in the paper [44]. For the current research on customer-industry engagement, the change management options investigated included "Off-Peak Tariffs and Managed Supply”, “Capital Spend”, “Insulation”, “Price Increases”, “Acknowledgement \& Recognition”, “Appliances (minimum performance standards)” and “Time of Use Tariffs”. These are provided in Table 1.

\subsection{The Customer-Industry Engagement Sub-Model}

This study focused on the social dimension of the REPDM model and, specifically, investigated the impact of education and engagement activities on the impact on peak demand reduction. Figure 2 highlights the elements

Table 1. Change management options applied through retail market and government policy interventions.

\begin{tabular}{|c|c|}
\hline Change Management Options (CMO) & $\begin{array}{l}\text { Strategic initiatives designed to change or influence consumer } \\
\text { behaviour to reduce or shift electricity demand especially during peak periods }\end{array}$ \\
\hline Off-Peak Tariffs and Managed Supply & $\begin{array}{l}\text { Off-peak tariffs \& managed supply; Where appliances are hard wired to } \\
\text { off-peak or other methods including through smart of managed supply }\end{array}$ \\
\hline $\begin{array}{l}\text { Capital Spend } \\
\text { Insulation }\end{array}$ & $\begin{array}{l}\text { Understanding that there is a need to spend capital to save energy; } \\
\text { Provide customers with ease of access to household power management for } \\
\text { products or initiatives such as Solar PVs, Household modernisation } \\
\text { including insulation, efficient pool pumps, alternative hot water of solar or gas }\end{array}$ \\
\hline Time of Use Tariffs & $\begin{array}{l}\text { Pricing structures tailored for consumers that are the most economical for them } \\
\text { generally and also the most effective at dampening electricity demand during peak } \\
\text { times or inducing load-shifting electricity demand away from peak times. } \\
\text { For example, retirees could benefit from a suitably structured time of use tariff } \\
\text { because they are able to undertake energy consumption activity away from peak times }\end{array}$ \\
\hline
\end{tabular}




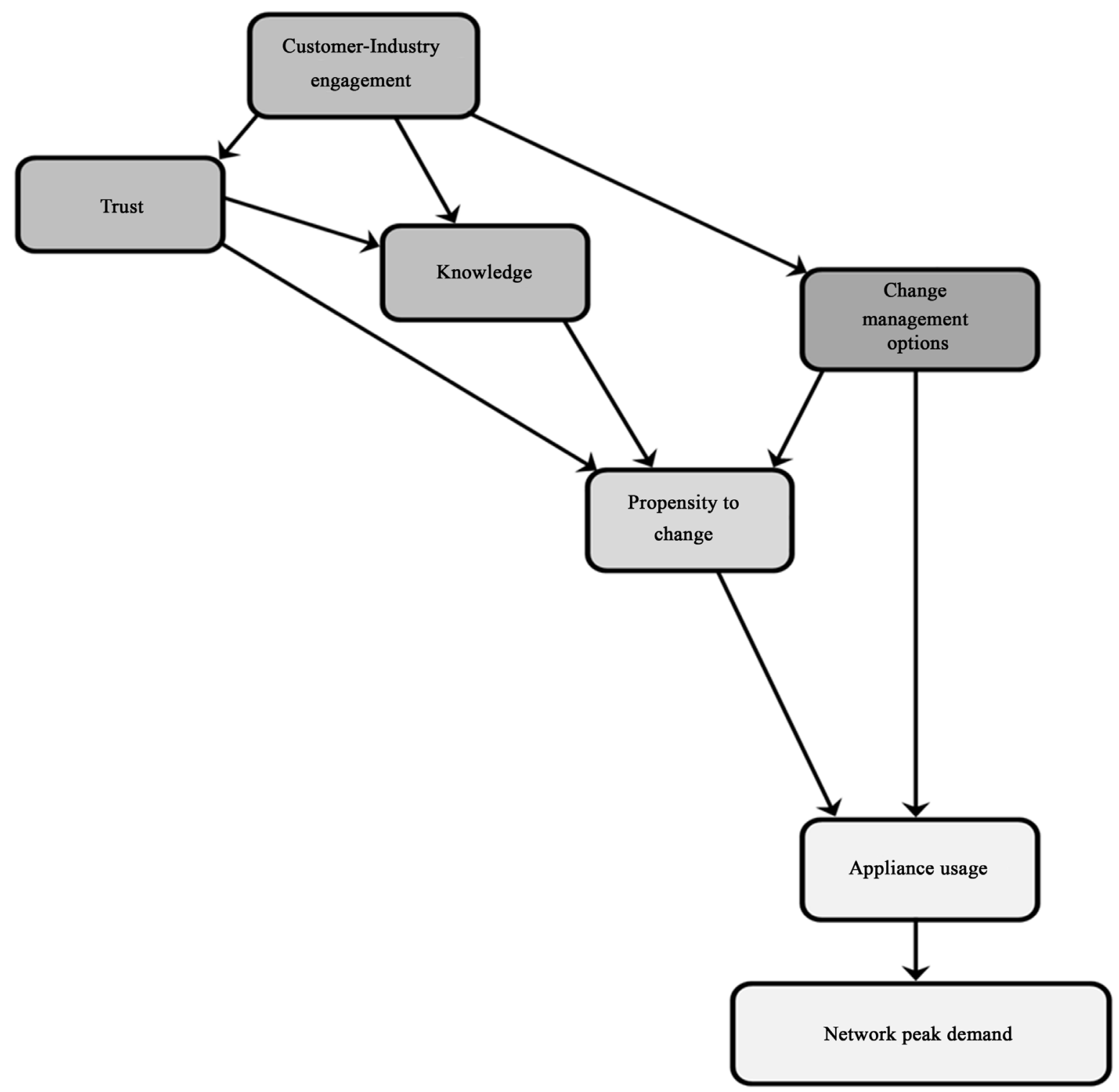

Figure 2. CIE other social dimensions of the REPDM model influencing peak demand.

of the social dimension that were considered. Within this component of the system presented in the REPDM, several of the nodes were sub-models, each potentially with a number of input and output nodes. The elements that make up these sub-models are described in Lewis, Mengersen [44]. The specific component of the full model that this paper investigated was the impact of Customer-Industry engagement through Local Community and Household focused activities. The CIE sub-model, with its Local community and Household sub-nodes, is shown in Figure 3. The separate education and engagement activities at the Local community and Household levels feed in to the Education and Engagement nodes which, in turn, influence the states of the CustomerIndustry engagement nodes.

Customer-industry engagement may involve education or engagement activities. These may be undertaken separately or combined at various levels with customers: at a local community level or at an individual household level. Whilst there are theoretically many different combinations of education and engagement possible, a smaller number of the different scenarios were considered. The levels of Customer-Industry Engagement used to investigate their combined impact on the states of the Propensity to Change node for each Change Management Option are listed in [44]. The different levels of the parent nodes of the sub-model were combined in the model 


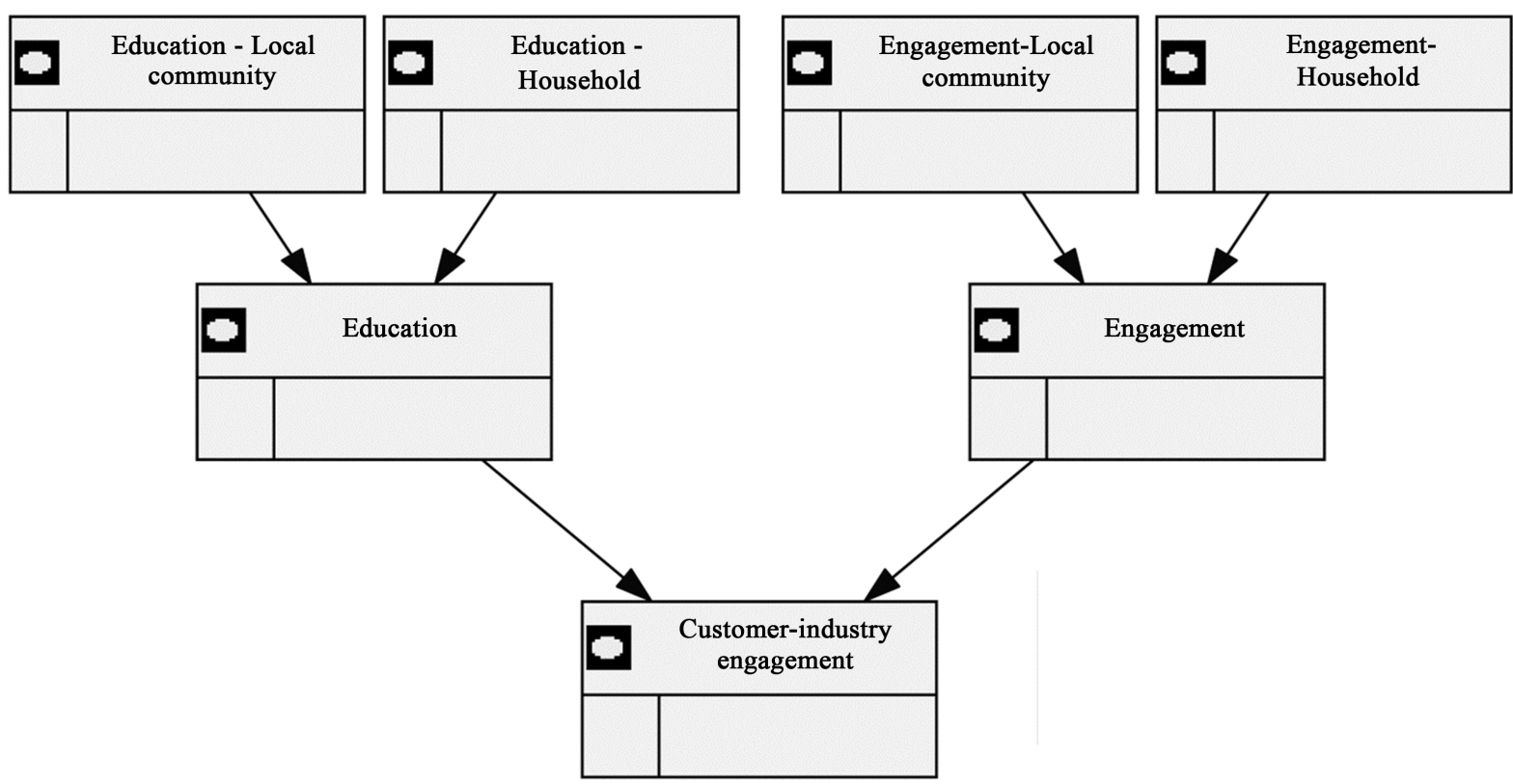

Figure 3. CIE sub-model nodes.

by first calculating states of separate Education and Engagement nodes and then bringing those together in the Customer-Industry Engagement node (see Figure 3).

\subsection{Other Aspects of the Modelling and Scenario Testing}

The elements of the REPDM that were not part of the scenario testing in this research were held constant. This included the technical aspects of houses etc. Within the social dimension, as the focus of this paper was on the impact of different scenarios of customer industry engagement, the states of the input nodes for Knowledge, Trust and Culture were also held constant [44]. The influence of the Household demographics element of the system was built into the model through the level of the consumption of electricity by households in the demographic cluster targeted by the CMO. The Environmental Sensitivity to Change, which addresses the context in which the interventions and decisions by a household were being implemented, was not considered in this component of the research. They too were thus no changed for the scenarios investigated.

It should be noted that this model was developed with most nodes having a Low or Nil state and a High state. Even with this restriction on the number of states, the size of the CPTs can be quite large. Although having additional states for the nodes would allow for increased variations in the model and include, for example, Very High and Extreme states, the model used did not provide this.

\subsection{Scenarios for Customer-Industry Engagement}

To observe the impact the modeled reduction in network peak demand, different levels of CIE activities may be applied. The states of each of the four Education and Engagement nodes of the sub-model may be set to provide for a range of levels of education and engagement activities. Five scenarios were selected to provide a range of CIE conditions for the modelling for this paper. The scenarios were chosen to focus on activities at the local community and the household levels. Activities at the broader community level were held constant. The scenarios investigated were:

1. Standard bill—General info on bill;

2. Advertising, personalised info on bill, norming against last bill, same time last year and sites to go to get information;

3. Advertising, personalised info on bill, norming against last bill, same time last year and sites to go to get information + markets and events booths in local community;

4. Advertising, personalised info on bill, norming against last bill, same time last year and sites to go to get info, 
markets and events booths in local community and with the addition of in-home audits and related activities;

5. Intensive engagement with local community to reduce peak demand (similar to an approach taken on Magnetic Island, Queensland, see [29]).

The levels of the input nodes in these scenarios range from a very low level Education activities and no engagement through to activities for Education at the Local Community and Household levels and Engagement activities at the Local Community and Household levels.

The levels of Education and Education activities for each of the scenarios were determined by the investigators based on the contributions to each facet by the scenario activities. To facilitate calculations, the states of the Propensity to change node in the model were calculated with these levels of Education and Education activities using the GeNIe implementation [44]. These outputs were then used in the Excel implementation to determine the impact on network peak demand that the model predicted for each of the CMOs.

\section{Results}

The impact of different interventions and their interactions with different levels of education and engagement activities were revealed through the model. The modelling of the scenarios using the quantified REPDM model yielded two main outcomes. The first was the different behaviour of the different change management options implemented. The second was that there were different responses to the addition of education and engagement activities with the different scenarios. The impact on network peak demand was calculated using the levels for the states of the Local Community and Householder activities for each scenario conducted and these are provided in Table 2.

\subsection{Scenarios for Customer-Industry Engagement}

The levels of the education and engagement activities for the different scenarios (Table 2) reflect that they provided increasing levels of education and engagement activities moving from the basic scenario, with Household education at $10 \%$ and all other nodes at $0 \%$, through to the most intensive engagement that could be implemented in the model. The scenarios increase in stepwise fashion. Scenarios 1 and 2 have only education activeties

Table 2. Five scenarios with different levels of Customer-industry engagement activities.

\begin{tabular}{|c|c|c|c|c|c|}
\hline \multirow{2}{*}{\multicolumn{2}{|c|}{ Scenario }} & \multicolumn{2}{|c|}{ Education } & \multicolumn{2}{|c|}{ Engagement } \\
\hline & & LC & $\mathrm{Hh}$ & LC & $\mathrm{Hh}$ \\
\hline 1 & Standard bill—-General info on bill & - & $10 \%$ & - & - \\
\hline 2 & $\begin{array}{l}\text { Advertising, personalised info on bill, norming against last bill, } \\
\text { as well as norming with the same time last year and sites to go to get info }\end{array}$ & $40 \%$ & $30 \%$ & - & - \\
\hline 3 & $\begin{array}{l}\text { Advertising, personalised info on bill, norming against last bill, norming with same } \\
\text { time last year and sites to go to get info + developing an active involvement in local } \\
\text { community through local media and sponsorship of sporting clubs and local schools }\end{array}$ & $40 \%$ & $30 \%$ & $40 \%$ & $20 \%$ \\
\hline 4 & $\begin{array}{l}\text { Advertising, personalised info on bill, norming against last bill, norming with same time } \\
\text { last year and sites to go to get info., markets and events booths in local community } \\
\text { developing an active involvement in local community through local media and } \\
\text { sponsorship of sporting clubs and local schools + presence at local markets and event } \\
\text { booths in local community and promotion of availability of free home energy audits }\end{array}$ & $40 \%$ & $30 \%$ & $60 \%$ & $60 \%$ \\
\hline 5 & $\begin{array}{l}\text { Advertising, personalised info on bill, norming against last bill, norming with } \\
\text { same time last year and sites to go to get info., markets and events booths in local } \\
\text { community developing an active involvement in local community through } \\
\text { local media and sponsorship presence in local markets and event booths in local } \\
\text { community + establishing household level relationship through conducting free } \\
\text { in-home audit with personalised advice on how to reduce electricity demand, } \\
\text { help with a plan of how to achieve reduced electricity demand with stickers } \\
\text { for appliances, free energy saving light bulbs, etc.; setting agreed goal with householder } \\
\text { and posting the agreed goal in prominent position in the house }\end{array}$ & $100 \%$ & $100 \%$ & $100 \%$ & $100 \%$ \\
\hline
\end{tabular}

LC—Local community, Hh—Household level activities. 
that increase in intensity from 1 to 2 . Then for the Scenarios 3 and 4, increasing levels of engagement activities were added. Finally, Scenario 5 is an intensive education and engagement approach with the levels of Education and Engagement activities at the Local Community and Household level set at 100\% for all nodes.

\subsection{Change Management Options Combined with Different Scenarios}

The model was developed to calculate the reduction in network peak demand for each of the selected options. The reduction for each option using the values for the five scenarios in Table 2 is shown in Figure 4.

It will be noted that the response varied in level and in the combined effect of the increasing level of education and engagement activities from Scenario 1 through to 5 for "Off-Peak Tariffs" and for "Capital SpendInsulation" but none for "Time of Use Tariffs", "Price Increases" or minimum standards for Appliances.

The largest impact on network Peak demand was for the "Off-Peak Tariffs", followed by the activities to stimulate the installation of insulation. The impact of the other four options, "Time of Use Tariffs", "Acknowledgement and Recognition”, "Price Increases” and introducing minimum standards for "Appliances”, was lower for all scenarios.

It was observed as shown in Figure 4 that change with different CIE scenarios for the two interventions of "Off-Peak Tariffs" and "Capital Spend-Insulation" led to larger reductions with increasing education activities at the Local community and Household levels. Specifically, it was noted that for "Off-Peak Tariffs" there was an increase from $0.53 \%$ for Scenario 1 to $0.77 \%$ for Scenario 2. With the next scenario, Scenario 3, where there was an addition of engagement activities, there was a larger reduction in peak demand and a predicted larger impact from increasing the engagement levels from Scenario 3 to Scenario 4 compared to that for moving from 1 to 2 . With Scenario 5, the reduction in network peak demand was further increased but it was smaller than the previous increases. Thus, we observed that there was a break point in the impact of the scenarios when moving from only education activities to adding engagement activities, even at $40 \%$ for Local community and $20 \%$ at the Household level.

A similar pattern but lesser response to the scenarios of education and engagement activities was observed for the "Capital Spend-Insulation" option. The reductions changed from $0.29 \%$ to $0.79 \%$ reduction in peak demand.

The response for "Time of Use Tariff" and "Acknowledgement and Recognition" of the scenarios was very small or showed no increase after the Scenario 2 or 3, predicting that there was no impact with increasing the levels of education and engagement after those levels of interventions for these two interventions. The impact of both options increased slightly from their initial states of $0.23 \%$ and $0.12 \%$ respectively. Although the impact of "Time of Use Tariff" was nearly the same level as that for "Off-Peak Tariffs", it differs in that it did not increase in the same manner with increasing levels of education and engagement activities.

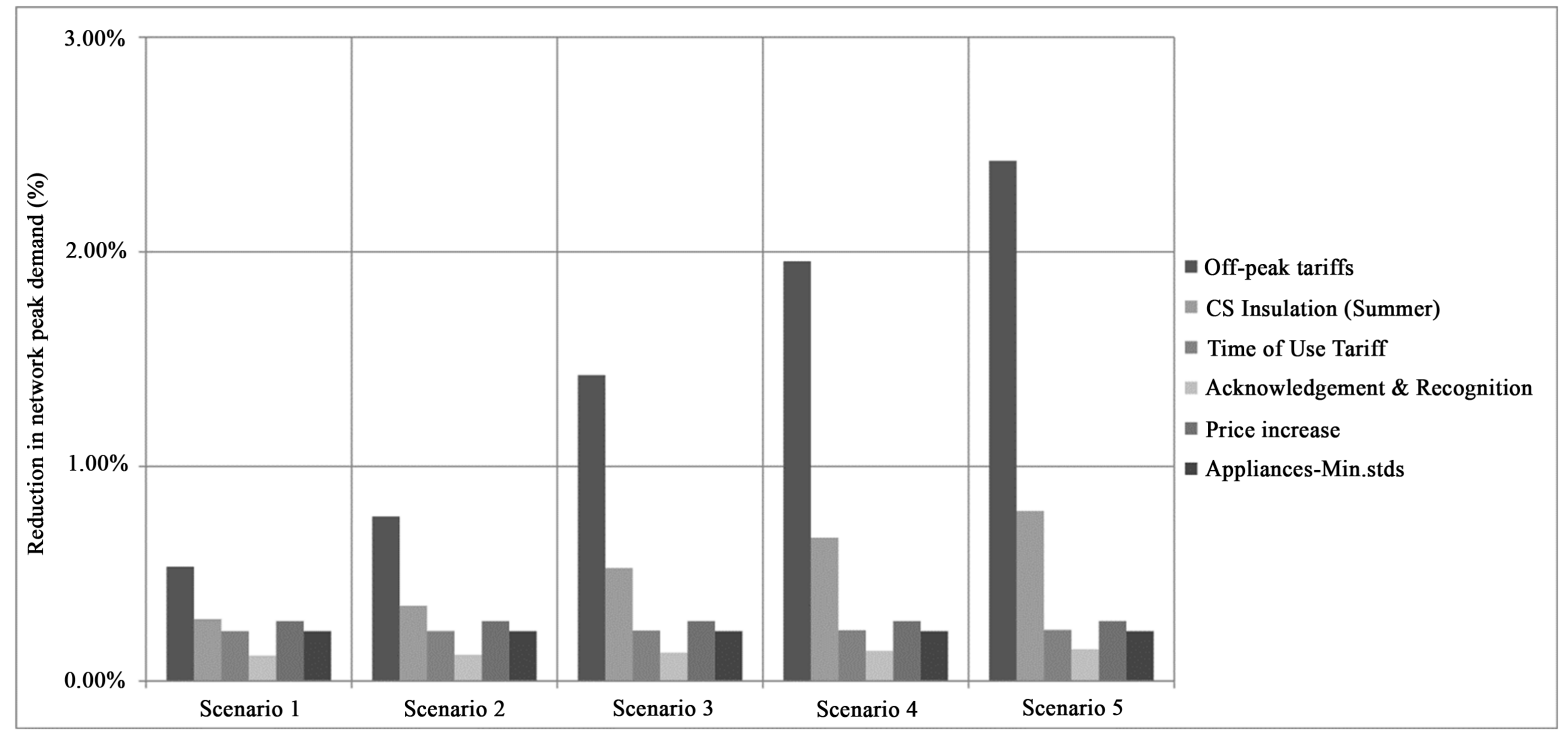

Figure 4. Reduction in peak demand (percent) for each of the scenarios. 
The responses for the other two options, "Price Increases” and “Appliances (minimum performance standards)" are the same for all scenarios. This is a reflection of the uniform CPT probabilities for all states of the parent nodes for the Propensity to Change nodes for each of these options. The model predicts a $0.28 \%$ and a $0.23 \%$ contribution to a reduction in peak demand with these change management options. Thus for the different interventions and the scenarios, it is notable that, as well as there being different responses in peak demand change between the options, there were also differences in the interaction with the different levels of the CIE activities represented by the different scenarios.

\section{Discussion}

There have been a variety of discipline specific strategies proposed to try and make sense of the problem of unabated residential electricity demand. These strategies have attempted to explain individual household electricity demand, how it varies and how it might be reduced with at best limited and/or short-term success. Chief among these is physical-technical-economic (PTE) strategies which dominate energy analysis and influence policy makers despite substantial evidence of poor performance in reducing residential electricity demand.

There are multiple, time varying factors that impact electricity demand in Australia's residential sector and the current model under review has been developed as a means to examine this complexity. The model is comprised of nodes and variables that are linked in a way that demonstrates each node's influence, impact or association with other nodes in the network. The model allows for each variable to be reviewed separately, within the complex system, as different factors impact on a consumer's desire or ability to reduce or shift electricity consumption. This review has examined the customer-industry engagement variable and its particular influence or impact on network peak demand. The values used in the model were made with the aid of research and some reasonably confident assumptions of the system through expert opinion and discussion, thereby utilising an integrated, cross-disciplinary approach. This data populated the complex systems BN model to scenario test the influence of the customer-industry engagement intervention on network peak demand. Five scenario evaluations were undertaken by modifying the change management options and probabilities in the $\mathrm{BN}$ in accordance with customer-industry engagement interventions.

\subsection{Customer-Industry Engagement (CIE) as a Contributor to Peak Demand Reduction}

Customer-industry engagement can be a powerful tool in influencing consumers and communities. The power of this influence was shown in a recent study by Morris and colleagues [29] where participants reported that engagement between the utility and them (the residents) fostered collaborative alliances which facilitated positive relationships and helped influence the community more broadly to significantly reduce their peak electricity demand over four or more years. Participants in the study highlighted mutual benefit as a means for behaviour change [29]. Although improvements to the relationship between utilities and their customers through engagement can reap significant reductions to peak energy demand, customer-industry engagement has been said to be limited to the rhetoric of deliberative engagement that does not transpire [31] or to communication between smart meters and the householder (for example see [32]-[34]).

To more fully understand the relevance or importance of residential customer-electricity industry engagement to peak electricity demand reduction, the current study examined its contribution to enhancing the outcomes of physical technical and economic initiatives. These initiatives or interventions were explored as Change Management Options (CMOs) within the REPDM through scenarios 1 to 5. Table 2 outlines the different scenarios ranging from basic education of general information through the electricity bill to more intensive education and engagement with households and the local community. The model showed that there were different levels of response for customer-industry engagement with different change management options. These ranged from significant to small to no response. The results show the importance of CIE to reducing peak electricity demand through its amplifying or fuelling effect on PTE initiatives or interventions. The model seems to show that CIE activities increases public support for residents reducing peak demand and this appears to be supported by previous research by Morris and colleagues [29].

\subsection{Significant Responses with CIE Activities}

There were two interventions that increased their impact on peak demand with the application of increasing levels of CIE in scenarios 1 through to 5. These were Off-Peak Tariffs \& Managed Supply and Insulation. 


\subsubsection{Off-Peak Tariffs \& Managed Supply}

The largest peak demand reduction from CIE activity, as output of the BN model, was the Off-Peak Tariffs \& Managed Supply CMO. This reduction grew in magnitude from a base of 0.53 percent with scenario 1 to 2.42 percent as a result of scenario 5 . This is a 4.55 fold increase. It would appear from these results that investment in CIE is defendable for Off-Peak Tariffs \& Managed Supply interventions. The result could reflect the benefit of the set and forget design of this intervention as previous research has shown that across many choice areas people rarely switch away from the option that requires no action [45]. Another possible reason for CIE being effective with this CMO is that for residents to adopt Off-Peak Tariffs \& Managed Supply they need to have confidence that they will not be impacted by the external management of their supply or energy availability. The more intensive CIE activities outlined for scenarios 4 and 5 could have increased (amplified) the penetration of the CIE activities of promotion, education and knowledge transfer of scenarios 1 to 3 . Through the engagement process of these latter CIE activities trust in the utility is established for the householder. Trust then precipitates confidence in the utility to the right thing by the resident. In the particular example of Off-Peak Tariffs \& Managed Supply, the householder has confidence that will have minimal or no impact from the external management of their supply.

\subsubsection{Insulation}

Insulation was also enhanced by the use of CIE but much less so than for Off-Peak Tariffs \& Management Supply. Insulation grew in impact with CIE activities for the different scenarios from a base of 0.29 percent to 0.79 percent with scenario 5 representing a 2.74 fold increase in peak demand reduction. This is particularly important given that energy efficiency behaviours (like installing insulation) are considered greater than that of curtailment behaviours [30]. Installing insulation is a one-shot behaviour requiring a capital spend investment for the purchase of energy-efficient equipment [16]. It, therefore, is also a set and forgotten type arrangement like off-peak tariffs. The results from this study indicate that education and engagement activities can precipitate the purchase behaviour of capital investment to improve comfort and to gain energy efficiency of the existing house. This result would suggest that utility spending in CIE activity is effective in enhancing the outcome from the economic intervention for energy efficiency investment. The effectiveness of CIE for this CMO also fits with the diffusion of innovation model [46]. Rogers [46] discovered that individual innovativeness is influenced by both the nature of the individual's social system as well as the individual's characteristics and these can be successfully influenced by targeted CIE activities (for example, see [29] [47]).

\subsection{Small Responses with CIE Activities}

Small responses in terms of impact on peak demand were found in testing scenarios 1 to 5 with increasing levels of CIE activities. These interventions were Acknowledgement \& Recognition and Time of Use Tariffs.

\subsubsection{Acknowledgement \& Recognition}

Through the scenario testing Acknowledgement \& Recognition grew in impact with the increasing levels of CIE activities outlined in Table 2 from a base of 0.12 percent to 0.15 percent. For the purpose of clarity, Acknowledgement \& Recognition as it relates to the REPDM was defined as positive affirmation activity specifically targeting low consumption and low payment risk profile householders. In a recent literature review on feedback, Vine and colleagues [20] outlined that acknowledging and recognising a low energy consumption profile with encouragement for a job well done has been shown to mitigate the risk of a boomerang effect. Schultz and colleagues [48] have shown that consumers who learn that they have lower than average consumption can inadvertently be encouraged to increase energy use because of the comparative standard. This is known as the boomerang effect. Such studies would appear to support the findings of this intervention resulting in a small response effect to increasing levels of CIE activities.

\subsubsection{Time of Use Tariff}

Time of Use Tariff grew in impact with CIE activities for the different scenarios from a base of 0.23 percent to 0.24 percent with scenario 5 representing a very small increase in peak demand reduction. What these results reflect is the minimal impact CIE activities have on residents who are reluctant or unable to change peak-time behaviour purely based on tariff. Darby [49] acknowledges the less than enthusiastic response of residential cus- 
tomers for time of use pricing based on utilities' short-term marginal costs where risk is transferred to the customer. Families and low-income households often have little scope for load-shifting with lifestyles that make it very difficult to change their consumption behaviours. Some consumers may be able to benefit from loadshifting incentives afforded by real time pricing. Retirees for example, could benefit from such a pricing structure by being able to undertake energy consumption activity outside of peak times.

\subsection{No Response with CIE Activities}

\subsubsection{Price Increase}

The model shows that Price Increase has a dampening effect on peak demand use, however, the model shows that increasing levels of education and engagement activities linked to price increases will have no impact. As with time of use tariffs, CIE activities will have little effect on residents who cannot change behaviour as a response to price increases. As noted above, low income households are significantly disadvantaged by increases in the cost of an essential service like electricity. These findings are also in keeping with a significant volume of previous research identifying the incongruity between rational economic efficiency and real behaviour of electricity consumption whether that be the behavioural response to economic incentives or penalties designed to reduce consumption [50] [51].

\subsubsection{Appliances (Minimum Performance Standards)}

This study indicates that CIE activities for Appliances (minimum performance standard) are not an effective short term strategy for achieving a reduction in peak energy demand. In Australia, minimum performance standards have been set for appliances and access to more energy-efficient appliances is increasing with the application of the Energy Star program which differentiates appliance models based on energy performance. However, investment costs for more efficient appliances that can substantially reduce operating costs are usually higher than less efficient appliances. This higher upfront cost is a disincentive for consumers who would otherwise prefer appliances that are more efficient to use over the lifecycle of the appliance [52]. Generally, consumers are unable to purchase a major appliance on the basis of energy efficiency in operation [53]. Consumers are often unaware of the amount of energy different appliances use or the energy lost through functions like standby especially as they purchase more appliances [52]. Adding to the confusion, is the aggregated nature of electricity bills across the billing cycle making it difficult for consumers to evaluate and consider the cost of particular appliance use of electricity. Therefore, while CIE would be ineffective in promoting minimum standard appliances, it could be useful in promoting the purchase of higher (than minimum standard) efficient appliances (see for example [29] [47]).

\subsection{Strengths and Limitations of the Model as It Relates to the Use of CIE Activities in Reducing Peak Demand}

The REPDM BN model is a useful tool to quantitatively and graphically explore and evaluate the interaction of particular intervention approaches like customer-industry engagement on other interventions within a package of reform targeting peak demand. CIE activity can be the transfer to households and the community of general knowledge of energy conservation and its benefits together with communicating information regarding any economic and/or technical interventions that are available.

Successful CIE activity allows for trust and a change culture to be established or developed. This result then enables the opportunity for personalised information transfer with access to the household. Such access allows for personalised information regarding economic, technical and behavioural solutions customised to the particular householder. It is therefore important given the potential positive impact of CIE as an intervention in and of itself as well as its boosting effect on other interventions (CMOs) that strategies to reduce peak demand seriously consider the addition of well designed and implemented CIE.

The model demonstrates that CIE activities need to be targeted to be most effective. This is to provide:

- Value for money. CIE activities can be expensive with intensive CIE activity being a significant investment. The study shows that where warranted CIE can significantly enhance other interventions (CMOs) and be significantly successful in terms of reducing peak demand and therefore averting the need for further major infrastructure development.

- Where to get the best value for money for CIE investment. The study shows that some CMOs did not re- 
spond to increasing levels of CIE activity. The model therefore highlights/identifies which interventions would provide the best outcome for CIE activity investment.

- Information for appropriate and cost effective policies and programs. The information provided from modelling allows targeted development of appropriate policies and programs through identifying the most cost effective CMOs or interventions.

In developing programs and policies, governments and utilities need to be cognisant of the nature of the intervention or CMO and the value that can be added from CIE that is well designed and executed with a plan that extends beyond an immediate timeframe. In their recent study, Morris and colleagues [29] identified the importance and success of CIE activities that extend over a number of years in significantly reducing peak energy demand within an Australian island community. Their study showed that the CIE activities built a partnership relationship with householders and the community more broadly that resulted in a significant reduction of peak demand that continued to decrease during the CIE phase. Morris and colleagues [29] found that the increase in support for peak reduction appeared to be a result of community connection with the energy utility through accessibility and long term commitment to the community of the utility's CIE activity. The current study model underestimates the extent of the peak demand decrease observed in the Morris, Buys [29] study as the model was not built to incorporate the extremely intensive interventions that were conducted within the island case study.

As well as the scenarios being chosen to investigate the Customer-Industry Engagement and holding the other elements of the system constant, the modelling also held the Broader Community Education and Engagement activities of this the CIE sub-model constant in the scenarios used. With the reduction in peak demand resulting from the modelling of Scenario 5, it should be noted that the model is designed with only two states for the Engagement and the CIE nodes. These are Low and High. To fully capture the level of interventions similar to those conducted on Magnetic Island, the model would need further states that could represent Very High or even Extremely High levels. As these states were not present, and the parameters were elicited for the Low and High states, the model was to likely understate the reductions that may occur through such interventions. Even though the scenario testing included only four change management options, and summing the reductions in peak demand for those options would not be as great as that with more options in the mix, the reduction in peak demand on Magnetic Island, where a combination of options, including education and engagement activities were undertaken, was far greater than the model estimated under Scenario 5. Addressing this underestimation could be considered in future iterative improvements to the model.

The current study model does not currently implement the different interventions (CMOs) to firstly, have different requirements for different types of Knowledge and Trust; secondly, the impact of the resultant levels of Knowledge and Trust following CIE activities will also vary with different CMOs and finally different CMOs may have sequencing influences and interactions [29]. These aspects are beyond the scope of the current model. However, the broad implications and the quantification that the current model allowed and the results examined in this paper from the running the model help reveal the synergies of combining education and engagement activities.

The REPDM BN model examined in this study could be enhanced by increasing nuances for each CMO and its parent nodes and their interaction. For example, the levels of trust, knowledge and culture are likely to be different for different CMOs. Further use and application of the model will help identify specific information gaps where targeted work could be applied to further strengthen the model. Better information will become available to provide values for the model and thereby adjust sensitivities of the construct of the model and improve the model's effectiveness of use and reliability of output. The REPDM BN model currently only provides a peak demand reduction for a given point in time. Further analysis is required to develop an understanding of the time dependency of results. Also, the model limits its focus to peak demand requiring further research to explore electricity consumption reduction more generally.

\section{Conclusion}

This study has provided insight into the importance of CIE in affecting residential peak electricity demand and the need for its inclusion in a more holistic approach to residential peak demand reduction. The model applied a systematic approach to explain and better understand the mix and types of interventions to achieve successful peak demand reduction. It quantitatively and visually represented CIE for each CMO element and showed how 
important CIE is to reduce residential peak electricity demand. In this paper, the REPDM BN model was able to quantify the benefit of customer-industry engagement on other change management options and its variable influence depending on the target intervention (CMO). The current study enhances the understanding of the benefit that can be derived from CIE through its impact on knowledge and trust and the value in developing programs which reflect the CIE requirement. The output from the model shows that there can be a strong interaction between the level of CIE activities and the CMOs. The influence of CIE activity can increase public and householder support for peak reduction and the model shows how the economic, technical and social CMOs can achieve greater peak demand reductions when well-designed with appropriate levels of CIE activities.

\section{Acknowledgements}

This research was supported under Australian Research Council's Linkage Project funding scheme (project number LP110201139). The findings and views expressed in this article are those of the authors and are not necessarily those of the Australian Research Council.

\section{References}

[1] Energy Rating. Managing Peak Demand.

http://www.energyrating.gov.au/about/other-programs/demand-response/

[2] Chester, L. (2012) Explainer: What Is Peak Power and How Does It Affect Prices? The Conversation, 2012.

[3] Moloney, S., Horne, R.E. and Fien, J. (2010) Transitioning to Low Carbon Communities—From Behaviour Change to Systemic Change: Lessons from Australia. Energy Policy, 38, 7614-7623. http://dx.doi.org/10.1016/j.enpol.2009.06.058

[4] Bartusch, C., et al. (2011) Introducing a Demand-Based Electricity Distribution Tariff in the Residential Sector: Demand Response and Customer Perception. Energy Policy, 39, 5008. http://dx.doi.org/10.1016/j.enpol.2011.06.013

[5] Guy, S. (2006) Designing Urban Knowledge: Competing Perspectives on Energy and Buildings. Environment and Planning C: Government and Policy, 24, 645-659. http://dx.doi.org/10.1068/c0607j

[6] Keirstead, J. (2006) Evaluating the Applicability of Integrated Domestic Energy Consumption Frameworks in the UK. Energy Policy, 34, 3065-3077. http://dx.doi.org/10.1016/j.enpol.2005.06.004

[7] Stern, P.C. (2011) Contributions of Psychology to Limiting Climate Change. American Psychologist, 66, 303-314. http://dx.doi.org/10.1037/a0023235

[8] Lutzenhiser, L. (1993) Social and Behavioral Aspects of Energy Use. Annual Review of Energy and the Environment, 18, 247-289. http://dx.doi.org/10.1146/annurev.eg.18.110193.001335

[9] Kowsari, R. and Zerriffi, H. (2011) Three Dimensional Energy Profile: A Conceptual Framework for Assessing Household Energy Use. Energy Policy, 39, 7505-7517. http://dx.doi.org/10.1016/j.enpol.2011.06.030

[10] Stern, P.C. (1999) Information, Incentives, and Proenvironmental Consumer Behavior. Journal of Consumer Policy, 22, 461-478. http://dx.doi.org/10.1023/A:1006211709570

[11] Hinchliffe, S. (1996) Helping the Earth Begins at Home. The Social Construction of Socio-Environmental Responsibilities. Global Environmental Change, 6, 53-62. http://dx.doi.org/10.1016/0959-3780(95)00113-1

[12] Wilson, C.M. and Price, C.W. (2010) Do Consumers Switch to the Best Supplier? Oxford Economic Papers, gpq006. http://dx.doi.org/10.1093/oep/gpq006

[13] Laitner, J.A. (2007) The Contribution of the Social Sciences to the Energy Challenge. ACEEE, Washington.

[14] Wilhite, H., et al. (2000) The Legacy of Twenty Years of Energy Demand Management: We Know More about Individual Behaviour but Next to Nothing about Demand. In: Jochem, E., Sathaye, J. and Bouille, D., Eds., Society, Behaviour, and Climate Change Mitigation, Kluwer Academic Publishers, Dordrecht; New York, 109-126.

[15] Heiskanen, E. and Pantzar, M. (1997) Toward Sustainable Consumption: Two New Perspectives. Journal of Consumer Policy, 20, 409-442. http://dx.doi.org/10.1023/A:1006862631698

[16] Abrahamse, W., Steg, L., Vlek, C. and Rothengatter, T. (2005) A Review of Intervention Studies Aimed at Household Energy Conservation. Journal of Environmental Psychology, 25, 273-291. http://dx.doi.org/10.1016/j.jenvp.2005.08.002

[17] Benders, R., Kok, R., Moll, H.C., Wiersma, G. and Noorman, K.J. (2006) New Approaches for Household Energy Conservation-In Search of Personal Household Energy Budgets and Energy Reduction Options. Energy Policy, 34, 3612-3622. http://dx.doi.org/10.1016/j.enpol.2005.08.005

[18] Shove, E. (2003) Comfort, Cleanliness, and Convenience: The Social Organization of Normality. Berg Publishers, 
Oxford.

[19] Hazas, M., Friday, A. and Scott, J. (2011) Look Back before Leaping Forward: Four Decades of Domestic Energy Inquiry. IEEE Pervasive Computing, 10, 13-19. http://dx.doi.org/10.1109/MPRV.2010.89

[20] Vine, D., Buys, L. and Morris, P. (2013) The Effectiveness of Energy Feedback for Conservation and Peak Demand: A Literature Review. Open Journal of Energy Efficiency, 2, 7-15. http://dx.doi.org/10.4236/ojee.2013.21002

[21] Wood, G. and Newborough, M. (2003) Dynamic Energy-Consumption Indicators for Domestic Appliances: Environment, Behaviour and Design. Energy and Buildings, 35, 821-841. http://dx.doi.org/10.1016/S0378-7788(02)00241-4

[22] Poortinga, W., Steg, L. and Vlek, C. (2004) Values, Environmental Concern, and Environmental Behavior: A Study into Household Energy Use. Environment and Behavior, 36, 70-93. http://dx.doi.org/10.1177/0013916503251466

[23] Abrahamse, W., Steg, L., Vlek, C. and Rothengatter, T. (2007) The Effect of Tailored Information, Goal Setting, and Tailored Feedback on Household Energy Use, Energy-Related Behaviors, and Behavioral Antecedents. Journal of Environmental Psychology, 27, 265-276. http://dx.doi.org/10.1016/j.jenvp.2007.08.002

[24] Steg, L. (2008) Promoting Household Energy Conservation. Energy Policy, 36, 4449-4453. http://dx.doi.org/10.1016/j.enpol.2008.09.027

[25] Ehrhardt-Martinez, K., Donnelly, K.A. and Laitner, S. (2010) Advanced Metering Initiatives and Residential Feedback Programs: A Meta-Review for Household Electricity-Saving Opportunities. American Council for an Energy-Efficient Economy, Washington DC.

[26] Ehrhardt-Martinez, K., Laitner, S. and Donnelly, K.A. (2011) Chapter 10-Beyond the Meter: Enabling Better Home Energy Management. In: Perry, S.F., Ed., Energy, Sustainability and the Environment, Butterworth-Heinemann, Boston, 273-303. http://dx.doi.org/10.1016/B978-0-12-385136-9.10010-5

[27] Burgess, J. and Nye, M. (2008) Re-Materialising Energy Use through Transparent Monitoring Systems. Energy Policy, 36, 4454-4459. http://dx.doi.org/10.1016/j.enpol.2008.09.039

[28] Parnell, R. and Larsen, O.P. (2005) Informing the Development of Domestic Energy Efficiency Initiatives an Everyday Householder-Centered Framework. Environment and Behavior, 37, 787-807. http://dx.doi.org/10.1177/0013916504274008

[29] Morris, P., Buys, L. and Vine, D. (2014) Moving from Outsider to Insider: Peer Status and Partnerships between Electricity Utilities and Residential Consumers. PLOS ONE, 9, e101189. http://dx.doi.org/10.1371/journal.pone.0101189

[30] Gardner, G.T. and Stern, P.C. (2002) Environmental Problems and Human Behavior. 2nd Edition, Pearson Custom Publishing, Boston.

[31] Cotton, M. and Devine-Wright, P. (2010) Making Electricity Networks "Visible": Industry Actor Representations of "Publics" and Public Engagement in Infrastructure Planning. Public Understanding of Science, 21, 17-35.

[32] Darby, S. (2010) Smart Metering: What Potential for Householder Engagement? Building Research \& Information, 38, 442-457. http://dx.doi.org/10.1080/09613218.2010.492660

[33] Honebein, P.C., Cammarano, R.F. and Boice, C. (2011) Building a Social Roadmap for the Smart Grid. The Electricity Journal, 24, 78-85. http://dx.doi.org/10.1016/j.tej.2011.03.015

[34] Lo, C.-H. and Ansari, N. (2012) The Progressive Smart Grid System from Both Power and Communications Aspects. IEEE Communications Surveys \& Tutorials, 14, 799-821.

[35] Wilson, C. and Dowlatabadi, H. (2007) Models of Decision Making and Residential Energy Use. Annual Review of Environment and Resources, 32, 169-203. http://dx.doi.org/10.1146/annurev.energy.32.053006.141137

[36] Lovell, H. (2005) Supply and Demand for Low Energy Housing in the UK: Insights from a Science and Technology Studies Approach. Housing Studies, 20, 815-829. http://dx.doi.org/10.1080/02673030500214118

[37] Ambroz, K. and Derencin, A. (2010) Using a System Dynamics Approach for Identifying and Removing Management Model Inadequacy. Kybernetes, 39, 1583-1614. http://dx.doi.org/10.1108/03684921011081187

[38] Kurtz, C.F. and Snowden, D.J. (2003) The New Dynamics of Strategy: Sense-Making in a Complex and Complicated World. IBM Systems Journal, 42, 462-483. http://dx.doi.org/10.1147/sj.423.0462

[39] Hovmand, P.S., Andersen, D.F., Rouwette, E., Richardson, G.P., Rux, K. and Calhoun A. (2012) Group Model-Building “Scripts" as a Collaborative Planning Tool. Systems Research and Behavioral Science, 29, 179-193. http://dx.doi.org/10.1002/sres.2105

[40] Korb, K.B. and Nicholson, A.E. (2010) Bayesian Artificial Intelligence. CRC Press, Boca Raton.

[41] Jensen, F.V. and Nielsen, T.D. (2007) Bayesian Networks and Decision Graphs. 2nd Edition, Springer, New York. http://dx.doi.org/10.1007/978-0-387-68282-2

[42] Van Raaij, W.F. and Verhallen, T.M.M. (1983) A Behavioral Model of Residential Energy Use. Journal of Economic Psychology, 3, 39-63. http://dx.doi.org/10.1016/0167-4870(83)90057-0 
[43] Buys, L., et al. (2015) A Framework for Understanding and Generating Integrated Solutions for Residential Peak Energy Demand. PloS ONE, 10, e0121195. http://dx.doi.org/10.1371/journal.pone.0121195

[44] Lewis, J., et al. (2015) Systems Modelling of the Socio-Technical Aspects of Residential Electricity Use and Network Peak Demand. PloS ONE, 10, e0134086.

[45] Allcott, H. and Mullainathan, S. (2010) Behavioral Science and Energy Policy. Science, 327, 1204-1205. http://dx.doi.org/10.1126/science.1180775

[46] Rogers, E.M. (2010) Diffusion of Innovations. 4th Edition, Simon and Schuster, New York.

[47] Morris, P., Vine, D. and Buys, L. (2015) Application of a Bayesian Network Complex System Model to a Successful Community Electricity Demand Reduction Program. Energy, 84, 63-74. http://dx.doi.org/10.1016/j.energy.2015.02.019

[48] Schultz, P.W., Nolan, J.M., Cialdini, R.B., Goldstein, N.J. and Griskevicius, V. (2007) The Constructive, Destructive, and Reconstructive Power of Social Norms. Psychological Science, 18, 429-434. http://dx.doi.org/10.1111/j.1467-9280.2007.01917.x

[49] Darby, S. (2006) The Effectiveness of Feedback on Energy Consumption. A Review for DEFRA of the Literature on Metering, Billing and Direct Displays.

[50] Jaffe, A.B. and Stavins, R.N. (1994) The Energy-Efficiency Gap: What Does It Mean? Energy Policy, 22, 804-810. http://dx.doi.org/10.1016/0301-4215(94)90138-4

[51] Weber, L. (1997) Some Reflections on Barriers to the Efficient Use of Energy. Energy Policy, 25, 833-835. http://dx.doi.org/10.1016/S0301-4215(97)00084-0

[52] Press, M. and Arnould, E.J. (2009) Constraints on Sustainable Energy Consumption: Market System and Public Policy Challenges and Opportunities. Journal of Public Policy \& Marketing, 28, 102-113. http://dx.doi.org/10.1509/jppm.28.1.102

[53] Brown, M.A. (2001) Market Failures and Barriers as a Basis for Clean Energy Policies. Energy Policy, 29, $1197-1207$. http://dx.doi.org/10.1016/S0301-4215(01)00067-2 


\section{Appendix 1}

The model development process is an iterative one, especially when using expert elicitation in Bayesian network implementations of complex systems. A review of the social science underpinnings and model behaviour as part of this process for the REPDM model has led to a number of changes. The modifications to the model relevant to this research were changes to the Conditional Probability Tables (CPTs) for the "Customer-Industry Engagement" and the "Price Increases-Propensity to change" nodes. The amended CPTs for these nodes are given below.

CPT for Customer-Industry Engagement

\begin{tabular}{cccccc}
\hline Education & High & & Low \\
\hline Engagement & High & Low & High & 0.75 \\
\hline High & 0.8 & 0.25 & 0.25 & 0 \\
Low & 0.2 & 0.75 & 0.7 \\
\hline
\end{tabular}

The CPT for Price Increases Propensity to Change

\begin{tabular}{ccc}
\hline Knowledge & For all states \\
\hline Culture & of all parent \\
Trust & nodes. \\
High & 0.05 & 0.05 \\
Low & 0.90 \\
\hline
\end{tabular}

The probabilities for the CPT for propensity to change with the Price Increases option were altered to be very low ( 0.9 for Nil and 0.05 for Low) for all states of the parent nodes. Further elicitation with industry experts was used to develop the CPT. The results in the states of the parent nodes had no impact on the propensity to change node which flows through to a uniform response for the reduction of network peak demand with any scenarios that result in changing the states of the parent nodes. 